\title{
Duchenne and Becker muscular dystrophy
}

INSERM

\section{Source}

INSERM. (1999). Orphanet: an online rare disease and orphan drug data base. Duchenne and Becker muscular dystrophy. ORPHA:262

Duchenne and Becker muscular dystrophies (DMD and BMD) are neuromuscular diseases characterized by progressive muscle wasting and weakness due to degeneration of skeletal, smooth and cardiac muscle. 